\title{
Perceived Water Quality and Reported Health among Adults during the Flint, MI Water Crisis
}

\author{
Daniel J. Kruger ${ }^{1}$, Suzanne Cupal $^{2}$, Gergana D. Kodjebacheva ${ }^{3,4}$, and Thomas V. Fockler ${ }^{5}$ \\ ${ }^{1}$ University of Michigan, Population Studies Center, Ann Arbor, Michigan \\ ${ }^{2}$ Genesee County Health Department, Flint, Michigan \\ ${ }^{3}$ University of Michigan-Flint, Public Health \& Health Sciences, Flint, Michigan \\ ${ }^{4}$ University of Michigan, International Institute, Ann Arbor, Michigan \\ ${ }^{5}$ University of Detroit Mercy, Health Services Administration, Detroit, Michigan
}

\begin{abstract}
Background and Purpose: In April 2014, the municipal water source for Flint, Michigan was changed from Lake Huron to the Flint River. Although residents reported concerns about the quality of tap water and resulting health problems, officials insisted that the water was safe. This study examined relationships between self-reported tap water quality during the water crisis and health conditions among Flint residents. Methods: Participants from each residential Census Tract in the City of Flint were recruited via address lists, online social media, and community-based events. The survey included mental and physical health items from the CDC's Behavioral Risk Factor Surveillance System and an item on tap water quarter quality experiences. Analyses were weighted to be demographically representative. Results: Participants $(N=277)$ rated their tap water quality (taste, smell, appearance) as Poor (57\%), Fair (20\%), Good (13\%), Very Good (6\%), and Excellent (3\%). Controlling for age, gender, years of education, whether respondents were African American or Hispanic/Latino/a, and population demographics, lower perceived tap water quality was associated with worse mental and physical health across all indicators. Conclusion: This study demonstrates associations of tap water quality experiences with reported poor physical and mental health among adults in Flint during the Flint Water Crisis.
\end{abstract}

(C) 2017 Californian Journal of Health Promotion. All rights reserved.

Keywords: Flint Water Crisis, water quality, community survey, community-based public health

\section{Introduction}

After decades of post-industrial economic decline (Hollander, 2010), the City of Flint was in receivership between 2011 and 2015, with city finances controlled by state appointed emergency managers (Bellinger, 2016; Staff, 2016). Regional municipalities approved the development of the Karegnondi Water Authority (KWA) to supply water from Lake Huron (Fonger, 2011).

While the KWA was under construction, local officials changed the water source from Lake Huron and the Detroit River (via the Detroit Water and Sewerage Department) on April 25, 2014 to the Flint River as a cost-saving measure (Staff, 2016). Officials failed to apply corrosion inhibitors, resulting in water contamination with lead and other substances (Associated Press, 2016; Hanna-Attisha et al., 2016).

Soon after the change in water source, community residents reported concerns about the smell, taste, and appearance of their tap water (Heavey, 2016). Some residents reported health concerns in adults and children, such as skin rashes and hair loss, which they attributed to contaminated tap water (Associated Press, 2015). Local residents mobilized beginning in Spring of

2014, organized marches and protests, 
attended municipal meetings, and reached out to media (Burke, 2016). However, Flint officials insisted that the city water was safe and that no link between water quality and health problems was evident (Associated Press, 2016).

The Speak to Your Health! Community Survey has been conducted biennially in Genesee County, Michigan since 2003 (Kruger, Shirey, Morrel-Samuels, Skorcz, \& Brady, 2009). This community-based participatory project monitors local health and health related concerns, assesses the influence of health initiatives on health outcomes, and promotes change to improve the health of Genesee County residents (Kodjebacheva, Koleilat, \& Kruger, 2015; Kruger et al., 2009). The survey results have previously been used to guide intervention programs (Kruger, Brady, \& Shirey, 2008) and leverage health policy changes (Kruger et al., 2009). The Survey Committee added an item on tap water quality experiences in the 2015 survey wave after the lack of official response to the water contamination, as previous health advocacy efforts were successfully facilitated by systematic survey results.

Consistent with recent survey waves, data collection began in September, 2015. Coincidently in the same month, reports of lead contamination in the water supply, elevated levels of child lead poisoning, and physician recommendations for Flint residents to stop using their tap water became public and attracted medial attention internationally (Associated Press, 2016). The Water Crisis and toxic contamination were regular features on local news and frequent topic of discussion among local residents. This project examines the association between poor tap water quality and adult health during great public concern regarding toxic water contamination.

\section{Methods}

\section{Study Design}

The University of Michigan Institutional Review Board for Health Sciences and Behavioral Sciences reviewed this project prior to data collection. This study was a cross-sectional community survey, with identical hard copy and online versions, designed by researchers with expertise in survey design and community partners serving on the Survey Committee. This current project focuses on data collected from October, 2015 through September, 2016.

\section{Participants}

The sampling frame Speak to Your Health! Community Survey is adult (18 years of age and older) residents of Genesee County, Michigan. Those who lived outside of Genesee County or were under 18 years of age were screened out of the study. The total sample size was 880 participants. The population of interest for this study is adult residents of Flint, Michigan with complete data for the analytic variables $(n=277)$.

\section{Measures}

The first section of survey items addressed health issues and included the physical and mental health items from the National Center for Chronic Disease Prevention and Health Promotion's (CDC) 2015 Behavioral Risk Factor Surveillance System (BRFSS), the nation's premier system of health-related surveys and the largest continuously conducted health survey system in the world. The CDC BRFSS included items on SelfReported Health (SRH), Self-Reported Mental Health (SRMH), Days when poor physical health interfered with daily activities (P days), and Days when poor mental health interfered with daily activities (M Days) out of the past 30 days. The water quality item was asked after all other items used in the analyses, "How would you rate the quality (taste, smell, appearance) of your tap water?,” with response options: Poor, Fair, Good, Very Good, and Excellent. 


\section{Procedures}

A marketing firm randomly selected 20 households in each residential Census Tract in the City of Flint based on US Post Office address lists. Households received postcard invitations to participate in the survey, which were followed by hard copy surveys and selfaddressed stamped envelopes. The response rate was 39\%. Participants were also recruited via e-mails to those who provided their contact information in previous survey waves, postings on electronic social media, and by local institutions forwarding to their e-mail lists. Participants could complete a hard copy survey or an online questionnaire.

The total population of the City of Flint was 99,802 according to 2011-2015 5-year estimates (U.S. Census Bureau, 2017). The racial/ethnic composition of the City of Flint in 2011-2015 was: 39.5\% White, 55.1\% Black or African American, 0.6\% American Indian/Alaska Native, $0.4 \%$ Asian, $0 \%$ Native Hawaiian and Other Pacific Island, 0.7\% some other race, and two or more races $3.7 \%$ (U.S. Census Bureau, 2017). During the same time period, $51.6 \%$ of people were female and 48.4\% were male in Flint (U.S. Census Bureau, 2017). Sample demographics were reviewed periodically for representativeness by age, sex, race, education, and geography, and supplementary recruitment events were held by community partners in neighborhood locations. Despite these efforts, African Americans were under-represented in the survey. Therefore, we used weighted analyses so that the results were demographically representative as discussed below.

\section{Analyses}

We created hierarchical linear regressions assessing the relationship between reported water quality and health outcomes. We entered socio-demographic characteristics in the first step, including age in years, sex, years of education, and whether respondents were African American or Hispanic/Latino/a. We allowed tap water quality to enter in the second step if it accounted for unique variance beyond that of socio-demographic characteristics. Analyses were weighted to be demographically representative based on age, gender, race, and educational attainment using the population estimates from the 2015 American Community Survey.

\section{Results}

\section{Participant Characteristics}

The analytic sample ( $n=277$, adult residents of Flint, Michigan with complete data) was predominantly female $(69.0 \%)$, white $(65.0 \%)$, and African American (24.4\%), with a mean age of 48 years, $S D=18$, range 18-94. Participants' average educational attainment was 13 years $(S D$ $=2$, range $6-20$ ), and $2.1 \%$ identified as Hispanic/Latino/a.

\section{Survey Findings}

Participants rated their physical health as Poor (5.1\%), Fair (24.5\%), Good (34.1\%), Very Good (27.1\%), and Excellent (9.2\%), and their mental or emotional health as Poor (3.3\%), Fair (15.4\%), Good (27.5\%), Very Good (36.3\%), and Excellent (17.6\%). Participants had an average of 4.2 days $(S D=7.9)$ when poor physical health interfered with daily activities and 2.1 days $(S D=5.9)$ when poor mental or emotional health interfered with daily activities out of the past 30 days. Participants rated their tap water quality (taste, smell, appearance) as Poor (57\%), Fair (20\%), Good (13\%), Very Good (6\%), and Excellent (3\%). Controlling for age, gender, years of education, whether respondents were African American or Hispanic/Latino/a, and accounting for demographic differences between the sample and population of interest, lower perceived tap water quality was associated with worse mental and physical health across all indicators (See Table 1).

\section{Discussion}

We found associations of perceived poorer tap water quality with reported worse physical and mental health. These relationships were independent of socio-demographic attributes known to be associated with health outcomes. 
Kruger, D.J., Cupal, S., Kodjebacheva, G.D., Fockler, T.V. / Californian Journal of Health Promotion 2017, Volume 15, Issue 1, 5661 .

Table 1.

Linear Regression of Health-Related Outcomes $(\mathrm{n}=277)$

\begin{tabular}{|c|c|c|c|c|c|c|c|c|c|c|c|}
\hline \multirow[t]{2}{*}{ Variables } & \multicolumn{5}{|c|}{ SRH } & \multicolumn{2}{|c|}{ SRMH } & \multirow{2}{*}{$\frac{\text { P days }}{\text { B }}$} & \multicolumn{3}{|c|}{ M days } \\
\hline & $\mathrm{M}$ & SD & $\%$ & B & $\mathrm{SE}$ & B & SE & & $\mathrm{SE}$ & B & SE \\
\hline (constant) & & & & $\begin{array}{l}2.67 \\
* * *\end{array}$ & 0.44 & $\begin{array}{l}2.45 \\
* * *\end{array}$ & 0.43 & $\begin{array}{c}14.34 \\
* * *\end{array}$ & 3.58 & $\begin{array}{c}10.76 \\
* * *\end{array}$ & 2.80 \\
\hline Age & 48.46 & 17.63 & & $\begin{array}{c}-0.16 \\
* * *\end{array}$ & 0.04 & -0.03 & 0.04 & 0.32 & 0.10 & -0.23 & 0.25 \\
\hline Sex & & & & 0.06 & 0.14 & -0.06 & 0.14 & -1.34 & 1.14 & 0.41 & 0.89 \\
\hline $\begin{array}{l}\text { Years of } \\
\text { education }\end{array}$ & 12.94 & 2.40 & & $\begin{array}{c}0.06 \\
*\end{array}$ & 0.03 & 0.05 & 0.03 & $\begin{array}{l}-0.64 \\
* *\end{array}$ & 0.24 & -0.36 & 0.19 \\
\hline $\begin{array}{l}\text { Black/African } \\
\text { American }\end{array}$ & & & 24.4 & 0.03 & 0.15 & 0.11 & 0.14 & -2.39 & 1.22 & -1.48 & 0.93 \\
\hline $\begin{array}{l}\text { Hispanic/ } \\
\text { Latino/a }\end{array}$ & & & 2.1 & -0.12 & 0.68 & 0.16 & 0.66 & -3.77 & 5.55 & -3.45 & 4.24 \\
\hline $\begin{array}{l}\text { Tap water } \\
\text { quality }\end{array}$ & 1.67 & 1.09 & & $\begin{array}{c}0.17 \\
* *\end{array}$ & 0.06 & $\begin{array}{l}0.24 \\
* * *\end{array}$ & 0.06 & $\begin{array}{c}-1.04 \\
*\end{array}$ & 0.52 & $\begin{array}{c}-0.94 \\
*\end{array}$ & 0.40 \\
\hline $\mathbf{R}^{2}$ & & & & & $10^{* * *}$ & & $89 * * *$ & & $82 * * *$ & & $.066^{* *}$ \\
\hline
\end{tabular}

Note: SRH = Self-Reported Health, SRMH = Self-Reported Mental Health, P days = Days when poor physical health interfered with daily activities out of the past 30 days, M Days = Days when poor mental health interfered with daily activities out of the past 30 days. For sex, 1 = female, 2 = male; for SRH, SRMH, and tap water quality, 5 = excellent, 4 = very good, $3=$ good, $2=$ fair, 1 = poor; for African American and Hispanic/Latino/a, $1=$ Yes, $0=$ No. Age in years was divided by 10 in analyses to facilitate interpretation of coefficients.

${ }^{*} \mathrm{p}<.05,{ }^{* *} \mathrm{p}<.01, * * * \mathrm{p}<.001$.

The findings of our study help extend coverage of health issues related to the Flint Water Crisis to adults; most of the current attention and public health response is focused on lead poisoning in children (e.g., Hanna-Attisha et al., 2016).

Water lead contamination is not limited to Flint, Michigan. At the Orange Center Elementary School located outside of Fresno, California, students have not been allowed to drink tap water for the past 2 years due to lead contamination (Newkirk, 2016). In 2016-2017, elevated levels of lead in water were discovered in 14\% of water outlets in 2,596 public schools in New York City, NY (Campbell, 2017). During the Washington DC Water Crisis (20002004), exposure to lead-contaminated drinking water was associated with higher rates of miscarriage, low birth weight, and fetal death (Edwards, 2014). A recent investigation found nearly 3,000 areas across the United States where rates of lead poisoning were at least double those in Flint during the water crisis (Pell \& Schneyer, 2016). Research is needed to assess the influence of lead contamination on individuals of different age groups and geographic locations.

These results may inform local community health efforts and advocacy for supportive services for community adults, in addition to efforts focused on children. This project demonstrates the value of community-based participatory efforts to inform local public health. Fortunately, other efforts revealed the 
Kruger, D.J., Cupal, S., Kodjebacheva, G.D., Fockler, T.V. / Californian Journal of Health Promotion 2017, Volume 15, Issue 1, $56-$ 61.

dangers of the contaminated water supply on children (Hanna-Attisha et al., 2016) while this project was under development. However, local hospitals could have responded to the concerns of community members, identifying the elevated levels of blood lead poisoning months earlier. Enacting preventative measures sooner after the change in water supply may have reduced the potential adverse health impacts of the contaminated water supply.

\section{Study Limitations}

Our results are cross-sectional rather than longitudinal. Thus, we examined the association between perceived tap water quality and reported health during the Flint Water Crisis. A limitation is that our study did not assess participants' blood lead levels. We used selfreported perceptions of tap water quality rather than assessments of toxicity levels. Our study did not separately assess the association between perceived tap water quality and health among vulnerable adults such as pregnant women and older adults. Additional studies are needed to confirm the results of this pilot cross-sectional investigation. Future studies should assess the longitudinal effects of the Water Crisis on health outcomes.

\section{Conclusion}

We hope that the widespread attention to the Flint Water Crisis helps prevent future similar incidents from occurring. If public health considerations were properly addressed in the management of the municipal water supply, the minimal financial investment in appropriate water treatment would have prevented a financial cost several orders of magnitude larger, as well as adverse influences on public health.

\section{Acknowledgements}

The 2015 Speak to Your Health! Community Survey was supported by the Blue Cross Blue Shield Foundation of Michigan, the Community Foundation of Greater Flint, and the Genesee County Health Department. We would like to thank the Speak to Your Health! Survey Committee members and all those who participated in the project for their assistance.

\section{References}

Associated Press. (2015, January 14). Flint city councilman: “We got bad water.” Detroit Free Press. Associated Press. (2016, January 16). A timeline of the water crisis in Flint, Michigan. Washington Post. Bellinger, D.C. (2016). Lead contamination in Flint: An abject failure to protect public health. New England Journal of Medicine, 374(12), 1101-1103. doi: 10.1056/NEJMp1601013

Burke, K.L. (2016). Moving forward after Flint. American Scientist, 104.3 (May/Jun), 137-139.

Campbell, J. (2017, January 30). Lead in schools: 14 percent of 236,000 NY water outlets test positive. Democrat \& Chronicle.

Edwards, M. (2014). Fetal death and reduced birth rates associated with exposure to leadcontaminated drinking water. Environmental Science and Technology, 48(1), 739-746. doi: 10.1021/es4034952

Fonger, R. (2011, May 10). DTE Energy tells new regional authority it may want 3 million gallons of Lake Huron water daily. Flint Journal.

Hanna-Attisha, M., LaChance, J., Sadler, R.C., Champney Schnepp, A. (2016). Elevated blood lead levels in children associated with the Flint Drinking Water Crisis: A spatial analysis of risk and public health response. American Journal of Public Health, 106(2), 283-290. doi: 10.2105/AJPH.2015.303003

Heavey, E. (2016). Lead poisoning: When an entire community is exposed. Nursing, 46(9), 28-33. doi: 10.1097/01.NURSE.0000490212.15944.5e

Hollander, J.B. (2010). Moving toward a shrinking cities metric: Analyzing land use changes associated with depopulation in Flint, Michigan. Cityscape, 12(1), 133-151.

Kodjebacheva, G., Koleilat, M., \& Kruger, D.J. (2015). Depressive symptoms mediate the association between fear of crime and higher body mass index. American Journal of Health Promotion, 30(2), 130-2. doi: 10.4278/ajhp.140103-ARB-6 
Kruger, D.J., Cupal, S., Kodjebacheva, G.D., Fockler, T.V. / Californian Journal of Health Promotion 2017, Volume 15, Issue 1, 5661.

Kruger, D.J., Brady, J.S., \& Shirey, L.A. (2008). Using GIS to facilitate community-based public health planning of diabetes intervention efforts. Health Promotion Practice, 9(1), 76-81. doi: $10.1177 / 1524839906293396$

Kruger, D.J., Shirey, L.A., Morrel-Samuels, S., Skorcz, S., \& Brady, J.S. (2009). Using a communitybased health survey as a tool for informing local health policy. Journal of Public Health Management and Policy, 15(1), 47-53. doi: 10.1097/PHH.0b013e3181903b9d

Newkirk, B. (2016, March 16). Don't drink the water: Lead found in California Schools. The Desert Sun.

Pell, M.B., \& Schneyer, J. (2016, December 19). The thousands of U.S. locales where lead poisoning is worse than in Flint. Thompson Reuters: Reuters Investigates. http://www.reuters.com/investigates/special-report/usa-lead-testing/

Staff. (2016, February 4). Disaster Day by Day: A detailed Flint crisis timeline. Bridge, the Center for Michigan.

U.S. Census Bureau (Accessed 2017, March 18). American Community Survey 5-Year Estimates, 2011-2015. Retrieved from:

https://factfinder.census.gov/faces/tableservices/jsf/pages/productview.xhtml?src=bkmk

Corresponding Author Information

Daniel J. Kruger, PhD

Population Studies Center

University of Michigan,

426 Thompson St.

Ann Arbor, MI 48109-1248

Phone: 734-936-4927

Fax: 734-763-1428

kruger@umich.edu 